\title{
LESSONS FROM A CUSTOMER-FUNDING REGIME IN A LARGE IT ORGANIZATION
}

\author{
Paul BALLINGER
}

\begin{abstract}
The author highlights 10 personal takeaways for a NATO IT Agency operating under a customer-funding mandate. Takeaways represent reflections from ten years of experience leading the financial management of the large not-for-profit NATO IT organization. The emphasis is on service delivery, cost efficiency, continuity, transparency, teamwork and community.
\end{abstract}

Keywords: Financial management, managing change, agility, transition, transparency.

\section{Introduction}

The NATO Communications and Information Agency (NCIA), as well as its predecessor - the NATO Consultation Command and Control Agency (NC3A), is not funded by the NATO budget, but by its customers. The introduction of customerfunding created an arms' length relationship between NATO Commands and Organizations and a NATO Agency with the stated objective to force more effective delivery, cost-efficiencies and transparency.

Work was contracted between the Agency and its customers on a fee-for-product or fee-for-service basis. Products and services were mainly firm fixed price, with a small percentage being cost (level-of-effort) reimbursable. The customer and the Agency were obliged to adhere to contract commitments, follow NATO contracting, personnel and financial policies and procedures, produce Annual Financial Statements and respond to governance by NATO Nations.

Ten takeaways regarding customer-funding are provided in this article, along with a comparison of a customer-funding regime with budget and private-sector models.

\section{Evolution of Applicable NATO Financial Policy}

The former NC3A (NATO Consultation Command and Control Agency), formed by the merger of procurement and scientific organizations, operated as a forerunner for 
customer-funding within NATO. The NCIA (NATO Communications and Information Agency) built upon the NC3A experiences and incorporated additional, previously budget-funded entities, into the new, larger Agency.

For NC3A, customer-funding was initially implemented with no change to the NATO Financial Regulations (NFRs). A derogation from the NFRs, approved later by Nations, became essential for Agency operations and for IBAN (International Board of Auditors for NATO) audit.

\section{Ten Key Takeaways Regarding Customer Funding}

\section{Improves Service Delivery ... Reinforced by "Corporate Discipline"}

Customer-funding forces positive change to all product and service delivery. The engagement of project and service leaders on the customer and agency sides creates a richly monitored and reportable environment. The organization and customers are constantly measured by delivery to written commitments and forced to adapt: gaps between commitment and delivery are measurable, manageable, auditable and must either be eliminated or mitigated.

In considering to operate under customer-funding it is imperative to recognize the cultural difference between budgeted work and work on contract, irrespective as to whether it is firm fixed price or cost reimbursable. Customer-funding requires significant additional discipline and communications, applicable to all contract participants. While the additional disciplines provide immense value, one should never underestimate the challenging learning curve for all concerned.

A start to improving service delivery is preparing a Product \& Service Catalogue clarifying specific parameters for work that may be performed by the customer focussed and funded entity, including key attributes and metrics.

Besides project personnel on both sides of the contract, the agency and the customer entity must ensure the product and service delivery is monitored by their respective COOs (Chief Operating Officer) for quality and delivery performance and their CFOs (Chief Financial Officer) for financial risk management and mitigation.

The NCIA is a multi-faceted large IT organization wherein product and service delivery requires approaches and processes specific to the subject matter. A significant difference exists among: scientific programmes of work enabling lessons to be learned from military operations and transformation actions; procurement and implementing large scale air defence and other capabilities; and providing a secure static and mobile IT infrastructure e.g. network connectivity, cyber defence, desktop, laptop, mobile phone services. Therefore, the customer facing processes must be tailored to specific subject matter requirements. 


\section{Improves Cost Efficiencies ... No Profit, No Loss}

Cost efficiencies, inefficiencies and waste are measurable through the customer-provider relationship and for the reported organization financial health overall. The notfor-profit mandate leads inevitably to constructive questioning and dialogue which, when addressed, forces cost improvements along with the service improvements.

Our customer-funded agency was mandated to break-even over a rolling 3 year period, with work performed charged by numerous negotiated contracts. Accounting requirements to reconcile contracts between customers and the agency ensure transparency and open both sides to criticism when warranted.

A sufficient Operating Fund is required for an agency to operate under customerfunding. The Operating Fund:

- Provides a repository or source for modest surplus or deficits within the reporting period together with essential working capital. Note: work on firm fixed price by definition rarely achieves precise no profit, no loss.

- Documents minimum and maximum levels within which the Operating Fund should fluctuate. These levels are decided by the governing body on recommendation of the Agency, with specific operating decisions delegated to Agency management.

- Insufficient Operating Fund funding means the NATO "owning" Nations might be required to contribute additional funds whereas too much funding implies funds are idled. In an era of Nation experiencing "tight money" neither alternative is desirable.

- Permits management level authority to improve the Agency through strategic planning. This means delegated authority to develop, fund and implement Strategy Implementation Projects (SIP) through the Operating Fund or annual overhead expenditures the details of which are transparently available.

An automated Project Management and Enterprise Resource Programme Software with supporting business processes is required. My experience is:

- Few staff are experienced in manual accounting processes. Therefore, there is a tendency to delay implementation until automation is fully available and implemented, somewhat disrespecting the potential of efficient and accurate interim solutions.

- A tendency to drive systems towards ever increasing levels of complexity and not to "keep it as simple as possible." This can easily drive costs up and delay successful implementations perhaps for years. 


\section{Transition ... Never Easy, Never Ending}

The cultural and physical challenges involved in transiting from one financial model to another should never be underestimated. Transiting from a budget to customerfunding model requires a multi-year transition period that includes:

- identifying and implementing changes to accounting and project management software;

- developing and implementing required business processes, including some manner of resource consumption identification and reporting;

- ensuring personnel on all sides of the relationship are trained, adapted and aligned to the new business processes;

- understanding and respecting the challenges operating a NATO entity comprised of personnel with diverse cultural backgrounds and experiences. Participants in the environment need to understand each other, to respect their cultural differences and yet develop common internal policies, procedures and processes, together with performance measurement metrics.

What is frequently ignored is that the transition never ends. There is a need:

- to constantly re-affirm and refine understanding of the customer-funding purpose, processes and metrics;

- to establish an ethic and environment of continuous improvement in work quality and delivery and financial management;

- to recognize the reality of turnover in personnel at all levels and components of the organizations, including the customers' authorities and contacts along with the NATO Nations' representatives' community.

\section{Three Year Rolling Financial Plan ... Launchpad for Success}

The financial plan for NCIA and NC3A was entitled the SPIE (Statement of Planned Income \& Expenditures), words specifically chosen to not include "budget," due to the nature of customer-funding.

The SPIE anchors internal and external communications relating to the customerfunded environment and the Agency's intended forward actions:

- Internally within the Agency it provides a focal point for internal planning based on several months of internal dialogue, including some heated discussions regarding priorities.

- Externally the Financial Plan provides a focal point for the dialogue between the agency, its customers and its governing bodies. 
- The financial plan clarifies the difference between resources dedicated to service delivery and resources dedicated to overhead, including what specific level of overhead is contained and is required.

- Whether for the product and service work or the necessary overhead support work, experience shows there is never sufficient funding to satisfy everyone. This was routinely evident in this not-for-profit organization. The only response is to open the dialogue regarding priorities and eventually in some areas to oblige staff to "live with it."

The Financial Plan ensures "facts" and "estimates," including underlying assumptions of forward contracts and business, are articulated and transparently visible to the extent needed for internal management and external governance.

Developing the Financial Plan requires a repeatable process (improved through experience) and is critical to success of the customer-funding regime. The process includes:

- A serious dialogue between the customer-funded organization and its customers provides insight into which quantified products and services will most likely feature in the customers' budgets and forward plans.

- Following that dialogue, overall key management assumptions and parameters are developed and documented.

- Key management assumptions include documentation of potential "worst," "best" and "planned" case scenarios providing insight into the judgements underpinning the plans.

- "Worst, best and planned" case scenarios anchor risk analysis and contingency planning on the basis that each scenario might occur.

- Risk analysis, followed by risk mitigation strategies and contingency planning, is key to management action and to retaining external governance confidence.

- The "worst case" scenario anchors the Agency response to a potential shortfall in anticipated revenue. For example, will resources be idled and create a deficit within the planning period. What will management do to mitigate the downside of this scenario?

- The "best case" scenario outlines the Agency response to a situation which in some ways is equally worrying. What if the Agency might not have sufficient resources to perform work the customers may be funded to contract with the Agency? This could harm the customers' own mandate success and cause long-term harm to the customer-supplier relationship. In this case 
customers must be engaged early to set priority, and may turn to a different organization to cover the shortfall.

- The "planned case" scenario anchors: a) development of customer chargeout rates and respective fees for the product and service delivery environments; b) documented annual and capital investments for upcoming years.

- It is normal to iterate a few versions of the financial plan internally and then submit the plan in advance to governing authorities for screening.

- With respect to the governing authorities it is useful to hold informal discussions with the Nations' representatives ahead of formal governing authority screening and approval. Informal discussions save time in committee and provides additional information to Nations requiring it.

- Conclusions from the Financial Plan also anchor recruitment, training and personnel decisions impacting the careers and contracts of employed personnel and contracted resources.

\section{Earning Confidence ... Governance, Reporting, Metrics}

There is no productive value when governing or customer bodies attempt to micromanage the customer-funded organization. On the contrary, micro-management undermines organizational effectiveness.

The GM (General Manager), COO \& CFO, together with other Executive Committee members, must earn and retain the confidence of governing bodies for their respective roles and be held accountable for results.

Finding an appropriate balance between micro detail and macro organizational performance represents a constant challenge:

- Individuals appointed to the governing bodies bring their national approaches and norms, some of which are highly bureaucratic.

- My experience is that there was almost always a tendency towards micro management, rather than macro governance. Nations' representatives, held accountable by their respective headquarters for value from their NATO contributions, often seek an increasing level of detail to help prove their diligence.

- However, pursuing too much detail may lead to a failure to hold the executives accountable for the agency's performance over time. Too much detail distracts from viewing the bigger picture, which requires action, and dilutes accountability.

The recommended approach is: 
- Agree in advance (with periodic update) a set of key corporate metrics which will be managed, measured and published. Examples include: customer satisfaction, delivery to agreed dates; cost and expenditure milestone achievement; and overhead identification and cost evolution.

- Publish metrics on the basis of recent history and projected into the forward planning period. Assuming progress on key metrics, confidence should follow with alternative action taken should key metrics demonstrate repeated failure or weakness of management.

- Schedule comprehensive discussion of Annual Reports and Financial Statements. Avoid a tendency to just await the IBAN Audit Report as that necessary focuses on compliance to regulations, not on leadership and management issues.

- Ensure management reports are issued minimally on a quarterly basis and trending towards "flash" monthly reporting. NATO management needs to learn from the best of the public corporations: regular updates to customers and governing bodies improves confidence in the entity.

\section{Transparent Communications ... Drive Success}

It cannot be overstated how important external and internal communications and dialogue are to successful Agency performance over time. This applies for product and service delivery and toward earning and retaining confidence of governing bodies. Mediocrity thrives in secretive environments.

My experience is that busy people often do not adequately plan and prioritize communications. Quality external and internal communications includes:

- Recognizing that external and internal communications is an essential management function at all levels of the organization, requiring a thoughtful and living strategy and plan.

- Realization that within the IT community participants often would rather prioritize on learning or refining their individual technical skills instead of communicating among co-dependent personnel within and across teams.

- Achieving open and transparently honest formal and informal two-way dialogue between Nations' representatives and the agency and between the NATO HQ staff and the Agency, noting that Nations often seek a "staff opinion."

Therefore it is imperative to have a viable and real internal and external communications strategy and plan promoting transparency. 


\section{Teamwork \& Recruitment ... Generate Energy}

The work of NATO involves teamwork at many levels. Thus, it is essential that $d y$ namic personnel management is in place to attract and retain highly qualified people, capable to work together. Equally this must be recognized as one of the keys to the success of the organization.

Selecting, training and retention of people with team skill must be attacked with precision:

- The NATO environment is characterized by frequent turnover of staff. This is desired and forced by some nations, especially for senior levels.

- Technology environments are still changing at light speeds often with the "best" people migrating to entities displaying aspirations to achieve state-ofthe art implementations.

- It is important to ensure corporate (team environment) competences grow along with individual competences to ensure overall team delivery outperforms the competencies of the individuals employed.

- Staff at all levels need individual performance achievement plans, to include competency acquisition, retention and refinement.

- Nations seek to be represented in the staff complement of the Agency, particularly for senior positions. Nations can help by ensuring upcoming career 3-6 year opportunities are widely "advertised" to qualified personnel within their Nation.

The return on investment in training individuals and teams provides almost instant value to the organization and to the professional satisfaction of team members.

\section{Contracting Choices ... Firm Fixed Price \& Cost Reimbursable}

The customer-funded organization must develop processes to provide both types of contract project management: firm fixed price and cost reimbursable. There are important differences especially relating to the upfront dialogue concerning service development and monitoring together with follow up customer satisfaction measurement.

Both approaches can and should work well. Having said that, my experience is that Firm Fixed Price provides the customer-funded organization and its customers better precision and flexibility, leading ultimately to higher customer satisfaction. The element and opportunity for surprise is reduced, if not eliminated. 


\section{Consultants \& Outsourcing ... Contribute Flexibility}

It is important for a customer-funded agency to undertake some work using outside consultants and/or to contract some work to an "outsourcer."

Recognizing that accountability for product or service delivery remains with the Agency, consultants and outsourcing demonstrates:

- Strategic and tactical use of consultants and outsourcing provides a level of flexibility over an approach to exclusively contract internal staff.

- Nations have varying policies regarding this topic. Some Nations prefer a higher percentage of staff personnel on contract whereas other Nations desire a higher use of consultants and outsourcing.

- All Nations monitor the use of consultants and outsourcers ensuring their Nations corporate providers experience a fair opportunity to "win" such business.

Beyond the use of consultants and outsourcing some Nations encourage the Agency's customers to compete the Agency programmes of work to industry and anticipate the Agency will be one of the competitors: This is much more complex than it would appear:

- Many of the industry participants claim to have subject matter expertise equal to NATO staff members ... it is extremely hard to determine the factual accuracy of these statements.

- Equally important is that industry participants are well aware that "buying the business" may create initial financial and performance problems for themselves, but the new situation will most likely keep additional business coming their way, once their staff come up to the work. This may create a level of industry dominance that is not in NATO's interest.

- Once the work of an Agency is outsourced to industry then the Agency may not have remaining critical mass to remain viable.

- If and when the Agency "wins the business" it is open to second guessing it for potentially having too much inside information. However should the Agency "lose the business" then it is open to "I told you so" irrespective of whether warranted or not.

It is important for the customer-funded organization to reach broad overall agreement with governing bodies on the extent of the usage of consultants and outsourcing, when the annual programme of work and financial plan are developed and agreed. 


\section{Respecting NATO Community ... Opens Opportunity}

The breadth of the NATO is complex, representing many approaches and characteristics that must be understood and respected for any component to be successful. This is particularly true for an Agency operating under a customer-funding regime and its customers, noting that the funding regime is relatively unique in NATO.

Among its characteristics, for NATO:

- The NATO HQ is an entity unto itself with an International Staff much of which is relied upon by Nations' representatives for disseminating information, recording decisions and regularly offering a "staff view" to help Nations understand required detail or situations.

- Although the Agency and its customers may have a sense of urgency for specific projects, that urgency is not always recognized by all participants whose influence is needed to drive timely action.

- There is regular turnover among: NATO HQ staff, Nations' Representatives to NATO, NATO Nation's Defence Departments tasked to monitor NATO programs and spending, NATO Commands, NATO Agencies.

- Depending on the Nation, there is annual or at least frequent turnover of those governing the Agency operating under customer-funding.

- Some Nations speak with a coordinated "single voice" in NATO Committees and Agency governing bodies whereas some speak through "multiple voices" depending on the subject at hand especially how important a specific topic is to a Nations' government.

- Some Nations display incredible "institutional memory" whereas others appreciate reminders to save time when staffing decision documents.

It is extremely useful for the customer-funded Agency executives:

- to discover if a representative's governing body needs additional information directly or indirectly and to follow up;

- to promote respect for the Nations as "owners of NATO" even though it may prove frustrating to have to provide rationale and justification multiple times;

- to recognize that when the above is well handled the work of the Agency is streamlined; decisions are received in a more timely manner.

\section{Conclusions}

Lessons learned over many years provide insight into the challenges and benefits and may be useful going forward. 
Financial management and accounting on behalf of 29 NATO Nations requires experience receiving and expending public funds and benefited from applying the disciplines of operating under a customer-funding regime.

While there is no perfect model to govern the operations and financial aspects of any large NATO or non-NATO IT organization, my experiences over 10 years with customer funding were highly positive.

Personal takeaway ... I am especially inspired by many NATO representatives, especially from the newer Member Nations, by their focus on the benefits to their countries of their membership in NATO. They spoke eloquently and passionately about the beacon for freedom and economic progress, which they attributed to NATO and its requirement to promote integrity and transparency. These representatives work extremely hard on behalf of NATO and their Nations.

\section{Two Tables Help Understand Customer Funding}

Table 1 provides an overview of the differences between budget and customer regimes within NATO.

Table 2 outlines the differences between private corporations and customer funding in the NATO context.

Table 1: Comparison of Budget and Customer Funding Regimes.

Budget Funding

Source of funds: Funding supplied by a NATO Financial Committee directly to a NATO Agency. Such funding often relates to the operations and management of the entity and not so much to the output.

Obtaining increases in funds: Requires a business case to funding authorities. Normally this is only possible to obtain on an annual basis unless a NATO crisis occurs. A tendency is to fully utilize all available funding, with special emphasis on spending at year-end.
Customer Funding

Source of funds: NATO Financial Committees provide funding to NATO Command and organizations, which in turn provide funding to the customer funded entry on a fee for service basis.

Thus the customer funded agency receives NATO funding indirectly, expect funding directly from NATO Nations.

Obtaining increases in funds: The customer funded agency is required to search for its customers beyond those that are currently in place. Equally it must ensure to balance its resources to continue to deliver to current customers or risk jeopardizing ongoing revenue streams. 
Conduct of work: Little if any work is conducted for non-NATO organizations. Some work may be completed for NATO Nations but in a budget funded environment this may not be possible, depending on the Agency's mandate.

Developing a programme of work: Military Commands build a case for a POW that is specifically identified with the Agency. The governance is provided by NATO HQ and also by the NATO governing policy and funding committees.

Flexibility of Command: NATO Military Commands do not have a meaningful choice of suppliers for the POW but together with policy and funding committees exert significant influence.
Conduct of work: The customer funded entity is specifically encouraged to find alternative sources of funding for work from NATO organizations and NATO Nations. Normally restrictions to disallow competition with the private sector.

Developing a programme of work: This is quite similar to the budgeted programme of work wherein Military Commands approach their financial committee for their requirements for funds and then prioritize within the funded period. However, there is additional bilateral work for NATO Nations which may fluctuate significantly.

Flexibility of Command: Over time, and under prescribed policy direction, the commands may compete and contract out some of their POW to industry or other Agencies. This provides the Military Command much greater influence over the Agency.

Table 2: Comparison between Private and NATO Customer Funding.

Private Corporation

\section{NATO Agency Operating Under Customer Funding}

Report: To a Board of Directors and to SubCommittees of the Board e.g. budget, audit, compensation, regulatory compliance. Board governance changes over time, but not normally quickly.

Negotiate Personnel Policies: Establish internal personnel policies and negotiate individual salary levels and benefits with staff. Changes may occur at managements' discretion.
Report: To a Board of Directors or Supervising Board comprised of representatives of all NATO Nations. Normally few or no subcommittees. Board governance changes rapidly as Nations change their representatives.

Comply with Personnel Policies: With NATO Civilian Personnel Regulations (NCPRs) changes are made after lengthy committee dialogue and considerations. 
Independent Purchasing Policy: Established internally, subject to executive oversight.
Comply with Financial \& Procurement Policies: Obliged to comply with NATO Financial Regulations and Procurement Policies and Guidance. Possibly modification for the agency in some aspects but not often. Additional change challenging.

Governed Pricing: Normally a fixed pricing policy for each resource utilized on a project or for service delivery. Overheads applied "fairly" to all customers. is due to the market negotiations rather than directed policy. Thus for similar services many prices may exist, with specific pricing is market driven and competitively based.

\section{Acknowledgement}

The author acknowledges the commitment, work ethic, creativity and energy of colleagues of the NCIA (including former NC3A), of the Nations' representatives in various governing domains and of the customer bodies (including ACT \& ACO) we dealt with over the 10 years.

\section{Disclaimer}

Opinions expressed herein do not necessarily reflect the views of the NCI Agency, NATO and the NATO Nations but remain solely those of the author.

\section{References}

1.C-M(98)28 et Corrigendum 18 May 1998 noting the NAC approval 10 May 1998 of a report titled The Application of a Customer Funding Regime to the NATO C3 Agency.

2.PO(2002)109 23 Jul 2002: the document from the North Atlantic Council (NAC) adopting International Public Sector Accounting Standards (IPSAS), including the accrual and going concern assumptions, as the applicable accounting standards for all NATO entities effective as of the fiscal year 2006.

3. OCB(2004)0054-REV2 12017 May 2004: the approval document for the Financial Rules and Procedures approved by the NATO Budget Committee. 
4. C-M(2004)0038 8 Jun 2004: the document approving the modified set of NATO Financial Regulations applicable to the NC3A operating under an approved customer funding regime.

\section{About the author}

PAUL BALLINGER received a Masters Degree in Business Administration at the Ivey School of Business, University of Western Ontario, Canada. He was Financial Controller \& Director of Resources of the NATO C3 Agency (July 2002 - June 2012). Upon establishment of the NCI Agency, into which NC3A and other NATO entities were merged, he was appointed Interim Financial Controller (June-October 2012). Prior to and subsequent to NATO employment he worked at the executive level in the private sector in varied positions: Chief Financial, Chief Information, Marketing and Business Development. Previously he gained military experience during a 21 year military career in the Canadian Armed Forces. 